Кузьмичев Е. Н., Верхотуров А. Д., Евстигнеев А. И., Дроздов Е. А.

E. N. Kuzmichev, A. D. Verchoturov, A. I. Evstigneev, E. A. Drozdov

КОМПЛЕКСНОЕ ИСПОЛЬЗОВАНИЕ МИНЕРАЛЬНОГО СЫРЬЯ

КАК ОСНОВА ФОРМИРОВАНИЯ ШИХТЫ СВАРОЧНЫХ ЭЛЕКТРОДОВ ДЛЯ РУЧНОЙ ДУГОВОЙ СВАРКИ

\title{
INTEGRATED USE OF MINERAL RAW MATERIALS AS THE BASIS OF CHARGE OF WELDING ELECTRODES CREATING FOR MANUAL ARC WELDING
}

Кузьмичев Евгений Николаевич - кандидат технических наук, доцент кафедры «Локомотивы» Дальневосточного государственного университета путей сообщения (Россия, г. Хабаровск), тел 8 (4212) 407-076. E-mail : accord@festu.khv.ru.

Mr. Kuzmichev Evgenii N. - PhD of Engineering, Associate Professor, Locomotive Department Far Eastern State Transport University (Russia, Khabarovsk).E-mail: e_kuzmichev@mail.ru.

Верхотуров Анатолий Демьянович - доктор технических наук, профессор, главный научный сотрудник Института Водных и экологических проблем ДВО РАН (Россия, г. Хабаровск). E-mail: Verhoturov36@mail.ru.

Anatoly D. Verkhoturov - Doctor of Engineering, Professor, senior researcher at the Institute of Water and Environmental Problems, the Far Eastern Branch of the Russian Academy of Sciences (Russia, Khabarovsk). E-mail: Verhoturov36@mail.ru.

Евстигнеев Алексей Иванович - доктор технических наук, профессор, Заслуженный деятель науки РФ, проректор по научной работе Комсомольского-на-Амуре государственного технического университета (Россия, г. Комсомольск-на-Амуре). E-mail: offise@knastu.ru.

Mr. Alexey I. Evstigneev - Doctor of Engineering, Professor, Provost for Research at Komsomolsk-on-Amur State Technical University, bearer of the little «Honoured Worker of Science and Engineering of Russia» (Russia, Komsomolsk-on-Amur).

Дроздов Евгений Александрович - кандидат технических наук, доцент, кафедры «Подвижной состав железных дорог» Дальневосточного государственного университета путей сообщения (Россия, г. Хабаровск), тел 8 (4212) 407-656. E-mail: vag6@festu.khv.ru.

Mr. Drozdov Evgenii A. - PhD of Engineering, Associate Professor, Rolling Stock Department Far Eastern State Transport University (Russia, Khabarovsk). E-mail: vag6@festu.khv.ru.

Аннотация. Приведены результаты исследований по разработке покрытых электродов для ручной дуговой сварки, особенностью которых является использование минеральных ассоциаций Дальневосточного региона. Предложена новая методика синтеза шихты покрытий электродов общего назначения, основанная на генерировании многообразия составов с последующим выбором рационального.

Summary. The authors displayed results of working out the covered electrodes for the manual arc welding. The specific feature is the use of mineral associations of Far East region. The new technique of charge synthesis for covering electrodes of the general purpose is based on generating a variety of structures with the subsequent choice of the rational variant.

Ключевые слова: восстановление деталей; электрод; покрытие, шихта; свойства; минеральное сырье.

Key words: restoration of details; an electrode; a covering, charge; properties; mineral raw materials. 
КУЗьМИЧев Е. Н., ВЕРХотУРОв А. Д., ЕвСТИГНЕев А. И., ДРОзДов Е. А.

КОМПЛЕКСНОЕ ИСПОЛЬЗОВАНИЕ МИНЕРАЛЬНОГО СЫРЬЯ КАК ОСНОВА ФОРМИРОВАНИЯ ШИХТЫ СВАРОЧНЫХ ЭЛЕКТРОДОВ ДЛЯ РУЧНОЙ ДУГОВОЙ СВАРКИ

\section{УДК 621.791-03}

\section{Введение}

Из практики известно, что большинство выбракованных по износу деталей теряют не более $2 \%$ исходной массы, при этом их прочность практически остается на прежнем уровне. В то же время до 80 \% деталей, выбраковываемых по износу, могут быть восстановлены до состояния, пригодного к дальнейшей эксплуатации, при этом себестоимость ремонта не превышает 65 - $70 \%$ стоимости новых деталей, а расход материалов на восстановление в 15 - 20 раз меньше, чем на их изготовление [1].

Анализ способов восстановления деталей технических устройств показывает, что наибольшее распространение (до 40 - 50 \%) имеют ручная дуговая сварка и наплавка покрытыми электродами, что требует пристального внимания к их разработке и производству.

В настоящее время промышленность поставляет более сорока типов покрытых металлических электродов [2]. Однако, несмотря на такое многообразие, проблема формирования требуемых заранее заданных свойств поверхностей, восстанавливаемых этим способом, в полной мере еще не решена по многим причинам, основными из которых являются следующие:

- каждый тип электрода предназначен для сварки или наплавки определенной группы сплавов с фиксированным химическим составом. Учитывая, что железнодорожный транспорт постоянно пополняется новыми конструкционными материалами, становится проблематичным подбор для их сварки и наплавки необходимого присадочного материала для формирования требуемых свойств. Кроме того, из-за малых оборотных средств и небольшой продолжительности срока годности потребители не в состоянии иметь регулярно пополняемый запас сварочнонаплавочных материалов широкой номенклатуры. Особенно болезненно этот фактор сказывается на небольших предприятиях;

- сварочно-наплавочные материалы производятся, как правило, на небольшом числе крупных предприятий монополистов, которые не могут оперативно реагировать на запросы предприятий железнодорожного транспорта;

- высокая стоимость наплавочных материалов не только по причине того, что в их состав входят дорогостоящие и дефицитные легирующие элементы (вольфрам, никель, кобальт, бор, хром и др.), но и потому, что основные производители находятся, как правило, в центральной части России и используют сырье, завозимое из отдаленных районов (Забайкалье, Урал, Западная Сибирь, Заполярье и др.). Кроме того, значительную часть приходится закупать в ближнем зарубежье (Украина, Узбекистан, Казахстан и др.). Увеличивает стоимость и транспортировка готовых материалов на большие расстояния.

Актуальность вопроса обеспечения промышленных предприятий качественными и недорогими сварочно-наплавочными материалами состоит в создании сравнительно небольших гибких производств, чутко реагирующих на постоянно меняющиеся запросы потребителей, максимально приближенных к сырьевым запасам, учитывающих особенности местного сырья.

Это особенно наглядно прослеживается в Дальневосточном экономическом районе, который обладает очень большими запасами минерального сырья, пригодного для производства высокоэффективных сварочно-наплавочных материалов. Здесь сосредоточено до 30 \% полезных ископаемых России.

В [3; 4; 5] отмечено, что горнодобывающая промышленность Дальневосточного региона занимает одну из ведущих позиций в добыче минерального сырья СНГ: борного - 90 \%, олова $80 \%$, золота - 50 \%, флюорита - 85 \%. Значительны запасы руд вольфрама, титана, свинца, цинка, бора, меди, графита и др. В целом в регионе выявлено более 70 видов полезных ископаемых.

Однако, несмотря на богатейшие и уникальные запасы минерального сырья, на сегодняшний день Дальневосточный регион не обладает необходимой базой для его переработки $[6 ; 7]$ и фактически является поставщиком вольфрамового, оловосодержащего, полиметаллического, борного и других видов сырья для западных регионов России и промышленно-развитых стран. Образовать же такую базу в короткие сроки весьма 
проблематично. Поэтому наиболее рациональным решением в настоящее время следует считать разработку относительно простых технологий получения материалов (в том числе сварочнонаплавочных) непосредственно из вырабатываемого горно-обогатительными комбинатами сырья, без его затратной переработки и реализовывать эти технологии непосредственно на предприятиях потребителях или небольших специализированных предприятиях, максимально приближенных к источникам сырья.

\section{Методика и материалы}

Современные электродные покрытия являются сложными многокомпонентными системами. Входящие в них материалы выполняют различные функции, причем очень часто одни и те же элементы одновременно решают несколько задач: защиту жидкого металла сварочной ванны от вредного воздействия окружающей среды, стабилизацию технологического процесса, раскисление, легирование наплавленного металла и ряд других. В общем случае они подразделяются на шлакообразующие, газообразующие, легирующие, раскисляющие, пластификаторы, стабилизирующие и связующие [8].

Наибольший объем в составе электродных покрытий занимают шлакообразующие (руды, концентраты, минералы), такие как гематит, магнетит, рутиловый концентрат, слюда, полевой шпат, мрамор и т.д. Из них целый ряд может быть использован одновременно в качестве газообразующих: мрамор, магнетит, доломит, известняк и др. Некоторые геологические материалы (слюда, полевой шпат, мел) можно применять в качестве ионизаторов.

Особый интерес представляет многокомпонентное минеральное сырье, которое может (наряду с решением отмеченных задач) осуществлять одновременно и легирование наплавленного металла. К такому сырью, например, относятся шеелитовый, баделеитовый, датолитовый и другие концентраты, в состав которых входят вольфрам, цирконий, бор и другие элементы, используемые для легирования стали.

Таким образом, из отмеченного видно, что имеющееся в регионе сырье дает возможность организации на предприятиях Дальнего Востока производства сварочно-наплавочных материалов широкой номенклатуры. В соответствии с изложенным разработаны электроды с покрытиями на основе минеральных ассоциаций Дальневосточного региона.

На первом этапе решалась задача создания электродов общего назначения для сварки углеродистых и низколегированных сталей, обеспечивающих следующие требования:

- хорошую комбинированную газошлаковую защиту сварочной ванны от воздействия внешней среды;

- качественную металлургическую обработку переплавляемого металла;

- легкое отделение шлаковой корки, малое разбрызгивание металла;

- свойства наплавленного металла не ниже свойств, получаемых при наплавке электродами типа Э-46А.

Формирование шихты покрытий электродов заключалось в генерировании многообразия составов с последующим выбором рационального.

На начальном этапе назначались компоненты шлаковой ванны, имеющие некоторую совокупность показателей $x_{1}, x_{2} \ldots x_{n}$, которые составляют неупорядоченное множество $Z_{y}$. Совокупность таких показателей отражает определенный набор вариантов состава шихты покрытий. Каждый вариант характеризуется n показателями, любое изменение которых порождает новый вариант. В этом случае формирование шихты покрытия сводится к выбору наиболее рационального варианта (для определенных условий использования электродов) из множества допустимых в соответствии с целевой функцией $y_{i}=f\left(x_{i}\right)$.

Следовательно, задачей формирования состава шихты является определение области существования системы $Z_{y}$, в которой находятся варианты, обеспечивающие получение параметров электродов, соответствующих нормативным требованиям и заданным свойствам наплавленного металла. 
Кузьмичев Е. Н., ВЕРХотУРов А. Д., ЕвСтиГнЕев А. И., ДРОзДов Е. А.

КОМПЛЕКСНОЕ ИСПОЛЬЗОВАНИЕ МИНЕРАЛЬНОГО СЫРЬЯ КАК ОСНОВА ФОРМИРОВАНИЯ ШИХТЫ СВАРОЧНЫХ ЭЛЕКТРОДОВ ДЛЯ РУЧНОЙ ДУГОВОЙ СВАРКИ

Анализ априорной информации показал, что планируемые свойства наплавленного металла могут обеспечить основные покрытия, так как при использовании рудно-кислых сложно выдержать заданный уровень содержания кислорода, серы и фосфора, а введение в покрытие органических составляющих способствует насыщению металла шва водородом, ведущим к образованию трещин. Из этого следует, что газовая защита может обеспечиваться $\mathrm{CO}_{2}$, являющимся продуктом диссоциации карбонатов $\left(\mathrm{CaCO}_{3}, \mathrm{MgCO}_{3}\right)$, а в шлаке должны преобладать основные окислы. Основная обмазка, обеспечивая технологические параметры и воздействуя на характер металлургической обработки жидкого металла сварочной ванны, оказывает положительное влияние на качество наплавленного слоя, обеспечивая защиту металла от вредного влияния воздушной среды, минимизирует в наплавленном слое содержание кислорода, азота, серы, фосфора, повышает ударную вязкость шва, снижает вероятность образования кристаллизационных трещин, дает возможность легировать наплавленный металл активными элементами.

За основу шихты покрытий электродов был принят известняк Вяземского месторождения Хабаровского края (см. табл. 1) по следующим основным критериям:

- обладает высокой шлакообразующей способностью;

- выделяет при температурах сварочной дуги до $42 \% \mathrm{CO}_{2}$;

- хорошо десульфирует жидкий металл;

- увеличивает основность шлаковой ванны.

Для поддержания на необходимом уровне вязкости жидкого шлака, его хорошей отделимости после кристаллизации, регулирования размеров и качества сварного шва в состав шихты введены флюорит Ярославского месторождения и гранит Корфовского разреза (Хабаровский край), которые одновременно являются шлакообразующими компонентами.

Таблица 1

Состав нелегирующего минерального сырья

\begin{tabular}{|c|c|c|c|c|c|c|c|c|c|c|c|c|}
\hline \multirow[b]{2}{*}{$\begin{array}{c}\text { Наименование } \\
\text { сырья }\end{array}$} & \multicolumn{12}{|c|}{ Состав, масс. \% } \\
\hline & $\mathrm{SiO}_{2}$ & $\mathrm{CaO}$ & $\mathrm{MgO}$ & $\mathrm{Al}_{2} \mathrm{O}_{3}$ & $\mathrm{FeO}$ & $\mathrm{Fe}_{2} \mathrm{O}_{3}$ & $\mathrm{Fe}_{3} \mathrm{O}_{4}$ & $\mathrm{Na}_{2} \mathrm{O}$ & $\mathrm{K}_{2} \mathrm{O}$ & S & $\mathrm{P}$ & $\begin{array}{l}\text { Про- } \\
\text { чие }\end{array}$ \\
\hline Известняк & 8,79 & 48,7 & 2,1 & 0,81 & - & 0,54 & - & 0,05 & 0,33 & 0,05 & 0,04 & 1,53 \\
\hline Гранит & 67,6 & 2,92 & 1,75 & 15,20 & 0,50 & 0,84 & 2,44 & 3,50 & 4,30 & 0,01 & 0,12 & 0,82 \\
\hline
\end{tabular}

В качестве раскислителей приняты наиболее распространенные при производстве электродов ферромтарганец и ферросилиций, а в качестве сердечника - низкоуглеродистая сварочная проволока Св08А.

При составлении шихты соблюдалось условие, чтобы основность шлака была более единицы, а активность находилась на уровне стандартных качественных электродов типа УОНИИ, т.е. в пределах $A=0,02 \ldots 0,04$.

\section{Результаты и обсуждение}

Головной эксперимент, включающий проверку одиннадцати марок электродов с основными покрытиями, средний состав которых приведен в табл. 2, показал их работоспособность, удовлетворительную технологичность, качественное формирование шва, чем доказана пригодность выбранного сырья для производства качественных электродов общего назначения. 


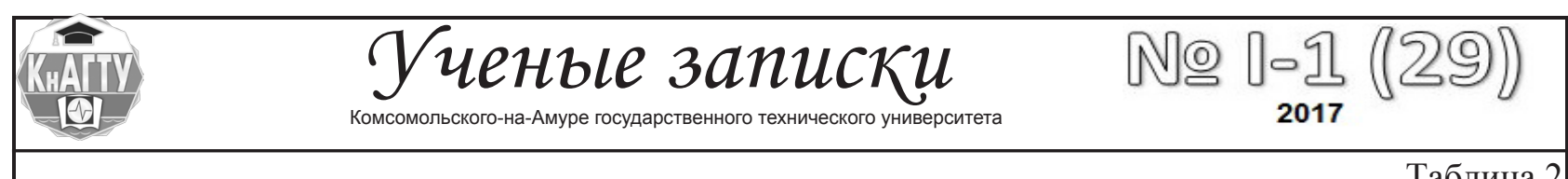

Состав покрытий опытных электродов (без сухого остатка жидкого стекла)

\begin{tabular}{|c|c|c|c|c|c|}
\hline Компоненты & Известняк & Гранит & Флюорит & Ферромарганец & Ферросилиций \\
\hline $\begin{array}{c}\text { Количество, } \\
\text { масс.\% }\end{array}$ & $50 \ldots 60$ & $10 \ldots 30$ & $15 \ldots 20$ & $3 \ldots 15$ & $2 \ldots 3$ \\
\hline
\end{tabular}

По результатам головного эксперимента установлены уровни входных факторов шлаковой системы и характер их влияния на выходной. В качестве входных факторов приняты гранит $\left(x_{1}\right)$, флюорит $\left(x_{2}\right)$, ферромарганец $\left(x_{3}\right)$, а в качестве выходного - коэффициент формы шва $K=b / a$, где $b$ - ширина наплавленного валика, мм; $a$ - высота усиления, мм. Этот коэффициент наиболее полно характеризует технологические свойства электрода, так как зависит от стабильности дугового разряда, глубины проплавления основного металла, текучести металла сварочной ванны, вязкости шлака, наличия чешуйчатости и др.

Для оценки коэффициентов полинома на основании составленного плана симплексной решетки реализовывались опыты, по результатам которых с помощью ЭВМ был определен его вид:

$$
\begin{gathered}
K=2,1 x_{1}+3,22 x_{2}+2,28 x_{3}+7,54 x_{1} x_{2}+2,88 x_{1} x_{3}+4,43 x_{2} x_{3}+8,89 x_{1} x_{2}\left(x_{1}-x_{2}\right)+ \\
9,58 x_{1} x_{3}\left(x_{1}-x_{3}\right)+4,75 x_{2} x_{3}\left(x_{2}-x_{3}\right)+73,46 x_{1} x_{2} x_{3},
\end{gathered}
$$

где $x_{1}, x_{2}, x_{3}$ - процентное содержание в шихте покрытий гранита, флюорита и ферромарганца соответственно.

Из множества вариантов, допустимых в соответствии с функцией (1), к дальнейшим исследованиям был принят электрод, имеющий коэффициент формы шва $K=6,2$, близкий к коэффициенту стандартного качественного электрода с основным покрытием УОНИИ 13/55К, для которого $K=6,42$.

Основность покрытия опытного электрода, химический состав которого приведен в табл. 3 , превышает основность УОНИИ 13/55К в 1,4 раза при активности $A=0,02$, что создает благоприятные условия для легирования наплавленного металла активными химическими элементами посредством их введения в шихту покрытий.

Таблица 3

Химические составы покрытий опытного стандартного электрода

\begin{tabular}{|c|c|c|c|c|c|c|c|c|c|c||}
\hline \multirow{2}{*}{ Электроды } & \multicolumn{9}{|c|}{ Компоненты, масс.\% } \\
\cline { 2 - 12 } & $\mathrm{SiO}_{2}$ & $\mathrm{CaO}$ & $\mathrm{MgO}$ & $\mathrm{CaF}_{2}$ & $\mathrm{Al}_{2} \mathrm{O}_{3}$ & $\mathrm{Fe}_{2} \mathrm{O}_{3}$ & $\begin{array}{c}\mathrm{Na}_{2} \mathrm{O} \\
\mathrm{K}_{2} \mathrm{O}\end{array}$ & FeMn & FeSi & FeTi \\
\hline Опытный & 9,61 & 46,9 & 6,60 & 23,0 & 0,59 & 0,65 & 0,96 & 7,00 & 3,00 & - \\
\hline $\begin{array}{c}\text { УОНИИ } \\
13 / 55 \mathrm{~K}\end{array}$ & 11,68 & 49,32 & - & 18,0 & - & - & - & 2,00 & 3,00 & 15,0 \\
\hline
\end{tabular}

Пониженное содержание в покрытии ферросплавов сокращает стоимость и улучшает технологию изготовления, так как исключается ряд ограничений, связанных с размерами частиц металлических порошков, вводимых в шихту покрытий: чрезмерное увеличение размеров (более 0,06 мкм) осложняет производство электродов, ухудшает технологические характеристики, а чрезмерное уменьшение может полностью аннулировать их основное назначение, так как такой порошок еще в стадии изготовления покрытия может окислиться за счет реакции с жидким стеклом. Присутствие $\mathrm{Al}_{2} \mathrm{O}_{3}$ и $\mathrm{Fe}_{2} \mathrm{O}_{3}$, входящих в состав гранита, отрицательного влияния на технологичность не оказывает. Наличие оксидов магния, натрия и калия увеличивает стабильность дуги. 
КУЗЬМИЧев Е. Н., ВЕРХОТУРОв А. Д., ЕвСТИГНЕев А. И., ДРОЗДОв Е. А.

КОМПЛЕКСНОЕ ИСПОЛЬЗОВАНИЕ МИНЕРАЛЬНОГО СЫРЬЯ КАК ОСНОВА ФОРМИРОВАНИЯ ШИХТЫ СВАРОЧНЫХ ЭЛЕКТРОДОВ ДЛЯ РУЧНОЙ ДУГОВОЙ СВАРКИ

Результаты термогравиметрических исследований экспериментального покрытия показали (см. рис. 1), что эффекты взаимодействия компонентов в интервале температур от 600 до $1000{ }^{\circ} \mathrm{C}$ имеют практически идентичный характер с таковыми в покрытиях стандартных качественных электродов УОНИИ 13/55К.

Изготовление покрытий и электродов в целом проводилось по стандартной технологии. Опытные наплавки осуществлялись электродами диаметром 3 мм на образцах из стали ВСт3 в семь слоев в нижнем положении постоянным током обратной полярности, силой тока $100 \mathrm{~A}$. В качестве источника питания использовался выпрямитель марки ВД 309.

a)

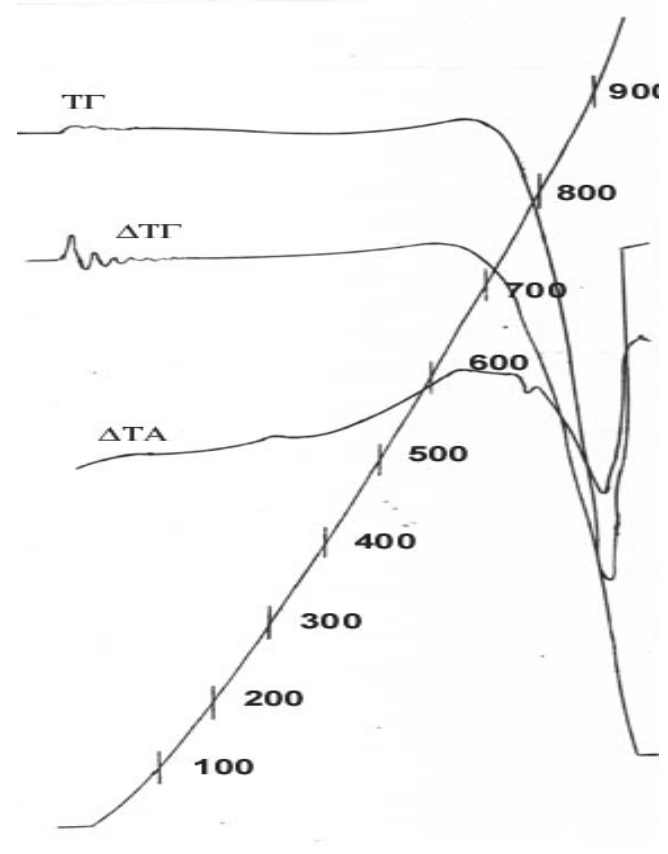

б)

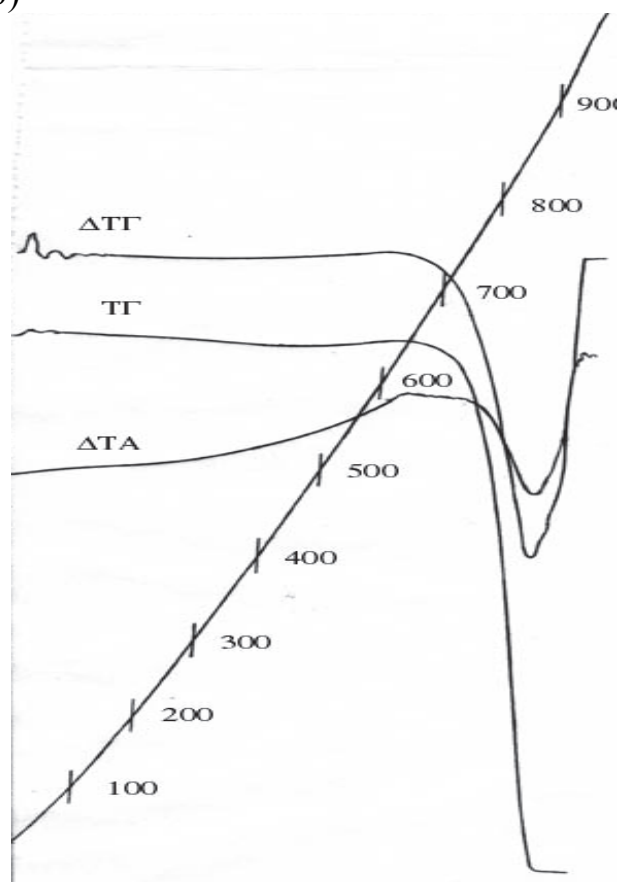

Рис. 1. Термограммы шихты покрытий электродов:

а - опытного; б - стандартного качественного УОНИИ 13/55К

Установлено, что у опытных электродов дуга горит устойчиво, разбрызгивание незначительное, формирование шва хорошее, чешуйчатость малая, отделение шлаковой корки легкое, горячие и холодные трещины на поверхности наплавленных валиков отсутствуют. В целом технологические свойства (см. табл. 4) практически совпадают со свойствами электродов УОНИИ 13/55К.

Таблица 4

Технологические свойства опытных электродов

\begin{tabular}{|c|c|c|c|c|c|c|c|}
\hline \multirow[t]{2}{*}{ Электрод } & \multicolumn{7}{|c|}{ Свойства } \\
\hline & $\begin{array}{c}\text { Коэффициент } \\
\text { расплавления } \\
\alpha_{p}, \text { г/Ач }\end{array}$ & $\begin{array}{c}\text { Коэффи- } \\
\text { циент } \\
\text { наплавки } \\
\alpha_{\text {н }}, \text { г/Ач }\end{array}$ & $\begin{array}{l}\text { Коэффи- } \\
\text { циент } \\
\text { потерь } \varphi\end{array}$ & $\begin{array}{c}\text { Длина } \\
\text { обрыва } \\
\text { дуги } \\
Z_{\text {обр, мм }}\end{array}$ & $\begin{array}{c}\text { Ширина } \\
\text { шва } b, \\
\text { мм }\end{array}$ & $\begin{array}{c}\text { Высота } \\
\text { усиления } \\
a, \text { мм }\end{array}$ & $\begin{array}{c}\text { Коэффи- } \\
\text { циент } \\
\text { формы } \\
\text { шва } K \\
\end{array}$ \\
\hline Опытный & 10,87 & 8,47 & 0,21 & 14,0 & 7,93 & 1,28 & 6,20 \\
\hline $\begin{array}{c}\text { УОНИИ } \\
13 / 55 К\end{array}$ & 10,64 & 8,53 & 0,19 & 12,0 & 8,45 & 1,32 & 6,42 \\
\hline
\end{tabular}


Наплавленный металл соответствует доэвтектоидной углеродистой стали с содержанием, мас.\% : углерода $0,11 \ldots 0,12$; марганца $0,7 \ldots 0,9$; кремния $0,25 \ldots 0,27$; серы $0,025 \ldots 0,03$; фосфора $0,02 \ldots 0,025$ и низкоуглеродистой литой стали, характерной для сплавов и покрытий, наплавленных стандартными качественными электродами общего назначения.

Механические свойства наплавленного металла (см. табл. 5) проверялись на стыковых сварных соединениях двух пластин из стали ВСт3 длиной 300 мм, шириной 100 мм и толщиной 16 мм каждая, с подваркой корня шва и на стандартных образцах при испытаниях на ударную вязкость.

Таблица 5

Механические свойства металла, наплавленного опытными электродами

\begin{tabular}{|c|c|c|c|c|c|c|c|}
\hline \multirow[t]{2}{*}{ Электроды } & \multicolumn{5}{|c|}{ Наплавленный металл } & \multicolumn{2}{|c|}{ Сварное соединение } \\
\hline & $\begin{array}{c}\sigma_{\mathrm{B}}, \\
\kappa г \mathrm{c} / \mathrm{MM}^{2}\end{array}$ & $\begin{array}{l}\delta \\
\%\end{array}$ & $\begin{array}{l}\alpha_{\mathrm{H}}, \mathrm{\kappa} \mathrm{c} \\
\mathrm{M} / \mathrm{cm}^{2}\end{array}$ & $\begin{array}{c}\alpha_{\mathrm{H} 45}, \text { кге } \\
\text { м } / \mathrm{cm}^{2} \\
T=-40^{\circ} \mathrm{C}\end{array}$ & $\begin{array}{c}\alpha_{\mathrm{H} 45}, \text { кГс } \\
\text { м/ } \mathrm{cm}^{2} \\
T=-60{ }^{\circ} \mathrm{C}\end{array}$ & $\begin{array}{c}\sigma_{\mathrm{B}}, \\
\text { кге } / \mathrm{MM}^{2}\end{array}$ & $\begin{array}{c}\text { Угол загиба, } \\
\text { градусы }\end{array}$ \\
\hline Опытные & 46,1 & 32,2 & 16,5 & 8,3 & 3,7 & 46,2 & 180 \\
\hline УНИИ13/55К & 46,8 & 33,4 & 17,2 & 8,6 & 3,9 & 46,5 & 180 \\
\hline
\end{tabular}

Сравнительный анализ полученных параметров показывает, что они совпадают с параметрами, полученными при сварке и наплавке стандартными электродами УОНИИ 13/55К (отличие не превышает $5 \%$ ).

Проведенный технико-экономический анализ показал, что стоимость разработанных качественных электродов общего назначения с основным покрытием за счет использования в шихте местного минерального сырья на 25 \% меньше закупаемых, а срок окупаемости участка производительностью три тонны в сутки составляет полтора года.

\section{Заключение}

1. Разработана методика синтеза шихты покрытий сварочных электродов общего назначения на основе комплексного использования минерального сырья Дальневосточного региона, учитывающая отклонения компонентов шлаковых систем от систем, предусмотренных нормативной документацией.

2. Созданы и экспериментально апробированы сварочные электроды с основной обмазкой из местного минерального сырья, обладающие технологичностью на уровне стандартных типа Э46А. Состав и механические свойства металла, наплавленного полученными электродами, соответствуют свойствам электродов УОНИИ 13/55К и могут быть использованы для получения покрытий при наплавке углеродистых и низколегированных сталей.

3. Технология изготовления созданных сварочно-наплавочных материалов проста, мало отличается от стандартной и может быть реализована на одном из предприятий железных дорог. Стоимость электродов общего назначения с основной обмазкой, в случае их производства на одном из ремонтных предприятий ДВЖД г. Хабаровска, на 25 \% меньше стандартных, а расчетный срок окупаемости при производстве электродов три тонны в сутки составляет полтора года.

\section{ЛИТЕРАТУРА}

1. Восстановление деталей машин: технология и оборудование / В. Е. Конарчук, А. Д. Чигринец, О. Л. Голяк [и др.]. - М.: Транспорт, 1995. - 303 с.

2. Петров, Г. Л. Сварочные материалы / Г. Л. Петров. - М.: Машиностроение, 1992. - 280 с.

3. Цветков, Н. И. Природно-ресурсный потенциал Дальнего Востока / Н. И. Цветков // Экономическая жизнь Дальнего Востока. - 1993. - № 1(2). - С. 70-83.

4. Верхотуров, А. Д. Основы материалогии. Т. 1 / А. Д. Верхотуров, А. М. Шпилев, А. И. Евстигнеев. Владивосток: Дальнаука, 2012. - 654 с. 
Кузьмичев Е. Н., ВЕРХотУРов А. Д., ЕвСТиГнЕев А. И., ДРОзДов Е. А.

КОМПЛЕКСНОЕ ИСПОЛЬЗОВАНИЕ МИНЕРАЛЬНОГО СЫРЬЯ КАК ОСНОВА ФОРМИРОВАНИЯ ШИХТЫ СВАРОЧНЫХ ЭЛЕКТРОДОВ ДЛЯ РУЧНОЙ ДУГОВОЙ СВАРКИ

5. Верхотуров, А. Д. Основы материалогии. Т. 2 / А. Д. Верхотуров, А. М. Шпилев, А. И. Евстигнеев. Владивосток: Дальнаука, 2012. - 270 с.

6. Минакир, П. А. Региональная экономическая динамика / П. А. Минакир, О. М. Прокопенко. - Хабаровск: ДВО РАН, 2010. - $304 \mathrm{c}$.

7. Пегов, С. А. Устойчивое развитие в условиях глобальных изменений природной среды / С. А. Пегов // Вестник РАН. - 2004. - Т. 84. - № 12. - С. 1082-1089.

8. Сварочные материалы для дуговой сварки: справ. пособие: в 2 т. / Б. П. Конищев, С. А. Курланов, Н. Н. Потапов [и др.]; под общ. ред. Н. Н. Потапова. - М.: Машиностроение, 1989. - 544 с.: ил. 